\title{
Simulation and Experimental Investigation on the AE Tomography to Improve AE Source Location in the Concrete Structure
}

\author{
Yu Jiang, ${ }^{1}$ Feiyun Xu, ${ }^{1}$ Bingsheng Xu, ${ }^{2}$ Minping Jia, ${ }^{1}$ Jianzhong Hu, ${ }^{1}$ and Antolino Gallego ${ }^{3}$ \\ ${ }^{1}$ School of Mechanical Engineering, Southeast University, Nanjing 211189, China \\ ${ }^{2}$ School of Science, Nanjing University of Technology, Nanjing 210009, China \\ ${ }^{3}$ Department of Applied Physics, University of Granada, 18071 Granada, Spain
}

Correspondence should be addressed to Feiyun Xu; fyxu@seu.edu.cn

Received 12 February 2014; Revised 29 April 2014; Accepted 8 May 2014; Published 8 June 2014

Academic Editor: Qingsong Xu

Copyright (C) $2014 \mathrm{Yu}$ Jiang et al. This is an open access article distributed under the Creative Commons Attribution License, which permits unrestricted use, distribution, and reproduction in any medium, provided the original work is properly cited.

\begin{abstract}
Acoustic emission (AE) tomography, which is based on the time-travel tomography with $\mathrm{AE}$ events as its signal sources, is a new visualization tool for inspecting and locating the internal damages in the structures. In this paper, AE tomography is applied to examine a man-made damage in a typical heterogeneous concrete structure to validate its effectiveness. Firstly, the finite element (ABAQUS/Explicit) simulation model of the concrete structure with one damaged circle in its center is built, and the simulated AE signals are obtained to establish the AE tomography. The results show that the damaged circle in the created model can be visualized clearly with the AE tomography in its original location. Secondly, the concrete specimen based on the FE model is fabricated, and the pencil lead break (PLB) signal is taken as the exciting source for AE tomography. It is shown that the experimental results have good consistency with the FE simulation results, which also verifies the feasibility of the finite element model for AE tomography. Finally, the damage source location based on AE tomography is compared with the traditional time of arrival (TOA) location method, and the better location accuracy is obtained with the AE tomography. The research results indicate that AE tomography has great potential in the application of structure damage detection.
\end{abstract}

\section{Introduction}

Fatigue crack is one of the reasons for structural failures of infrastructures such as bridges and tunnels [1]. To avoid the failure of these structures, maintenance and inspection have to be carried out by different strategies [2]. Acoustic emission (AE) testing is an excellent tool of the risk-based inspection to detect the most degradation processes dynamically $[3,4]$. Coupled with this technique to diagnose early internal damage of structures, the visualization of the damaged location from the inspection is required [5].

Tomography is an emerging technique for nondestructive evaluation and aims to visualize the internal structure of various types of objects by using two- or three-dimensional representation, so that better identification of anomalous regions and determination of physical properties of the measured region can be achieved. The great advantage of this technique is used to obtain a precise noncontact measurement of internal structures [6]. The popular computer tomography (CT) based on X-ray, a classic method for medicine purpose, has also demonstrated highly promising implementation for characterizing structures constituents in the laboratory scale to enable reliable numerical study on the influence of different crack formations $[7,8]$. In terms of in situ application, the travel-time tomography has been widely applied [9]. This technique shares similar concept with the common seismic tomography, in which the arrival times of body waves (usually of primary, P-waves) from multiple ray paths are observed, collected, and then used as input for computing the distribution of wave velocity in association with each ray path within the meshed model [10]. In the travel-time tomography, the travel time of wave along a path is used as the observed data and the slowness (the reciprocal of wave velocity) is employed as the computed 

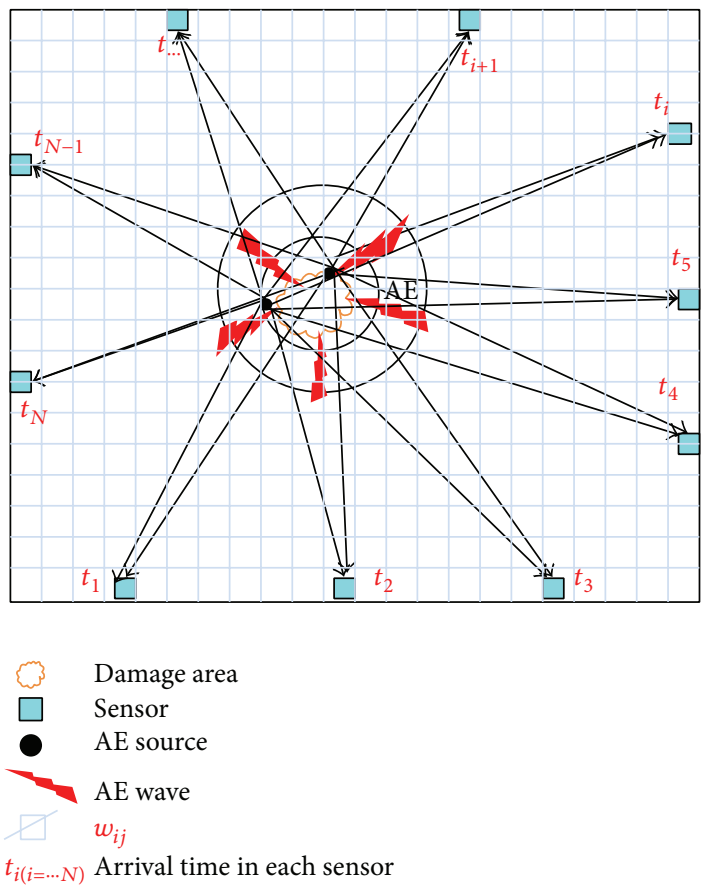

Figure 1: AE tomography model.

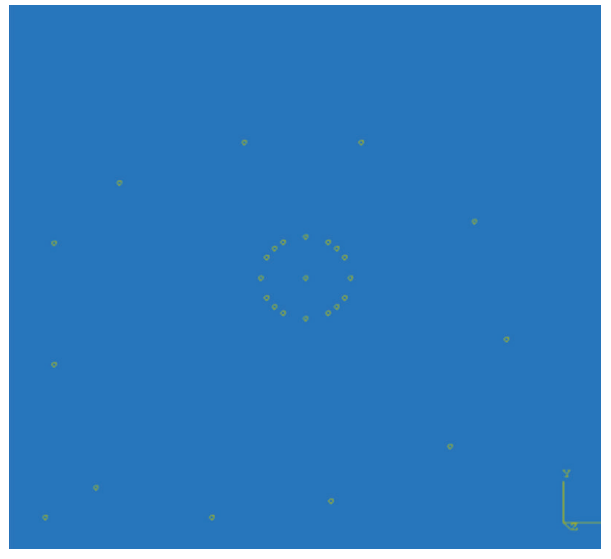

(a) 2D EF model

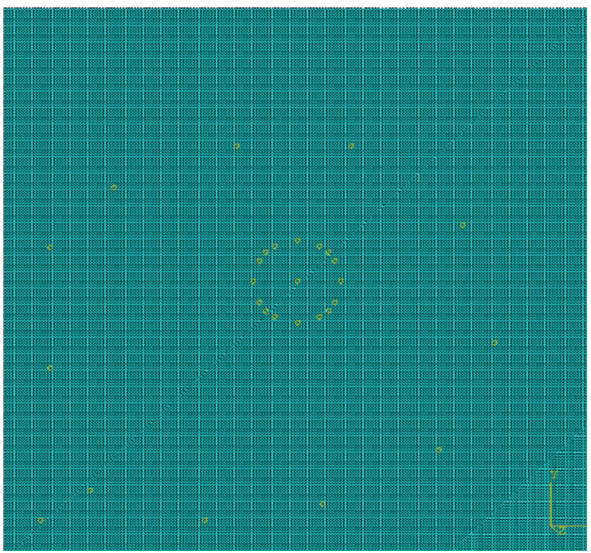

(b) 2D FE cell model

FIGURE 2: FE model of concrete structure.

property of the measured object [11]. To improve accuracy of the travel-time tomography and better detect the details of the internal damage of the object structures, more global and local property information distributions throughout object structures are all needed [12]. The AE testing technique combined with travel-time tomography would be developed and refined.

$\mathrm{AE}$ is an elastic wave generated due to crack occurrence or crack propagation, which is considered to be the only possible method for a global surveillance at the moment [13]. Source location is the key topic of AE testing method in order to reveal where the damage is occurring in a structure [14]. Traditional location methods such as time of arrival (TOA) location [15] and single sensor model analysis location
(SSMAL) [16] are always limited in a simple assumption; that is, wave travels at the same speed in all directions. The AE tomography can overcome these difficulties of traditional location algorithms. As a beneficial supplement for $\mathrm{AE}$ analyzing, AE source location and tomography techniques can be implemented simultaneously [17]. Related report is found regarding effective utilization of the technique for assessing the integrity of infrastructures [18]. The main motivation of this paper is to investigate the feasibility of the AE tomography to determine a wave-speed map and visualize the internal structures for damage characterization in heterogeneous concrete structure in term with locally varying wave speed distribution. The ultimate aim is to develop an alternative AE source location method to detect 


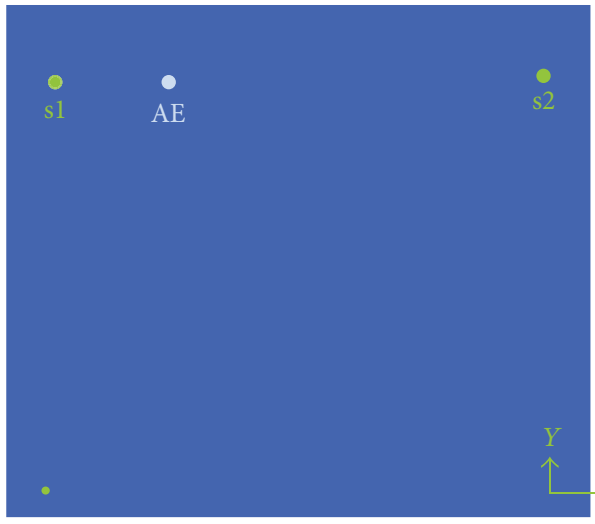

(a) Wave velocity measurement

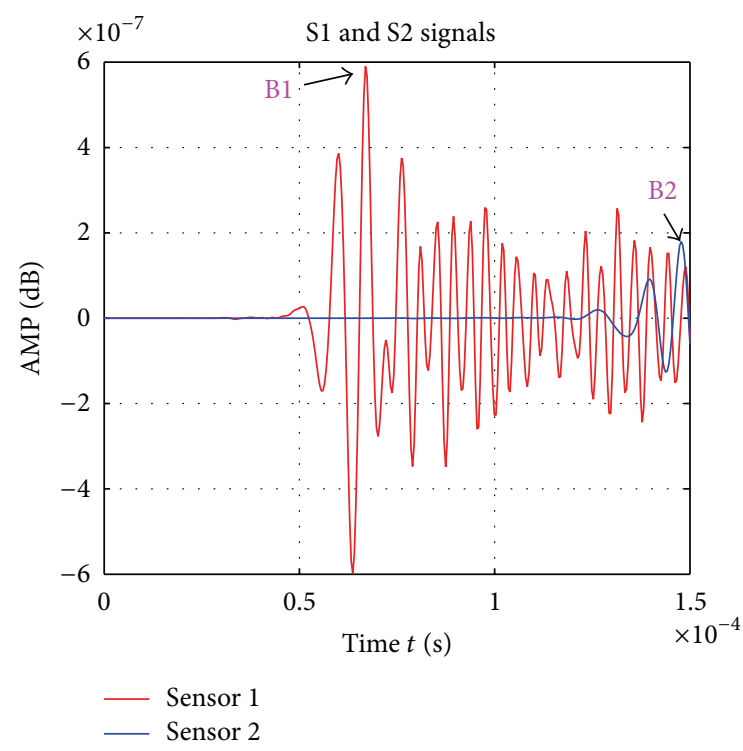

(b) s1 and s2 waveforms

FIGURE 3: Verification of the FE model (wave velocity).

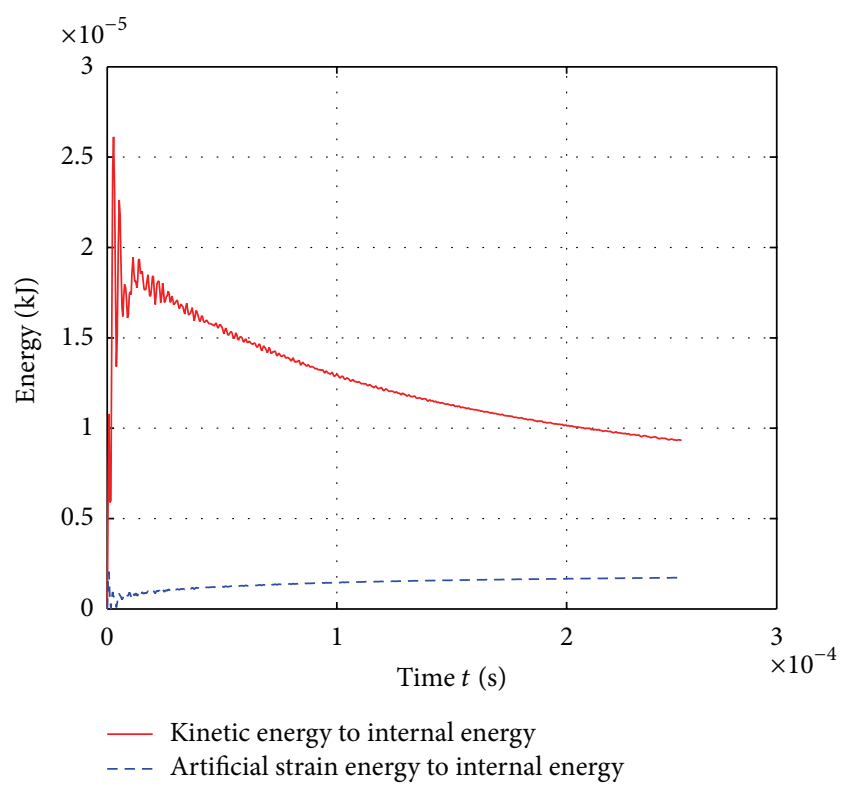

FIGURE 4: Verification of the FE model (energy).

and visualize the location of $\mathrm{AE}$ source in the interior of structure with highest possible accuracy.

\section{The Basic Principle of AE Tomography}

$\mathrm{AE}$ tomography uses the $\mathrm{AE}$ events as signal sources for the travel-time tomography, which contains source location algorithm and tomography algorithm $[19,20]$. This technique represents an important improvement on traditional AE data analysis. It not only leads to a new imaging technique that the $\mathrm{AE}$ sources positions in the specimen are visualized in terms of a locally varying wave speed distribution and also leads to significantly better localization of AE events.

2.1. AE Tomography Model. A bidimensional AE tomography model is shown in Figure 1. Modeling the region under study is subdivided into an array of cells and the propagation speed of AE signal in each cell is assumed to be a constant.

In the $\mathrm{AE}$ tomography model, a straight-ray model regarding the source-sensor travel path is also assumed. Once $\mathrm{AE}$ source is excited in the damaged area, the arrival time of signal is recorded at each sensor from 1 to $N$. Then, the time differences are calculated. The information is entered into a suitable tomography algorithm, and a mapping of $\mathrm{AE}$ tomography for the specimen is reconstructed.

2.2. AE Tomography Algorithm. In the AE tomography, the $\mathrm{AE}$ source location algorithm and tomography algorithm can be implemented simultaneously. The arrival time of the signals at each sensor is a function of the source location and of the propagation speed of the acoustic waves. As shown in Figure 1, the arrival time of the $\mathrm{AE}$ signal received at each sensor can be stated as:

$$
T_{k}^{A}=T_{k}^{0}+\sum w_{i j}^{k} \cdot s_{i j},
$$

where $k$ refers to each ray from the acoustic event source to each sensor $k=1,2, \ldots r,(i, j)$ is index indicating the position of each tomographic cell $i=1,2, \ldots, m ; j=1,2, \ldots, n$. $s_{i j}=1 / c_{i j}$ is the "slowness" of the signal propagation along the tomographic cell, defined as the reciprocal of its propagation speed $c_{i j}$. $w_{i j}^{k}$ represents the distance travelled by the $k$ th ray inside the cell $(i, j)$. Note that most of these elements are zero, since only a relative small number of cells are crossed by each ray. $T_{k}^{A}$ is the time of measured arrival of the signal from ray 


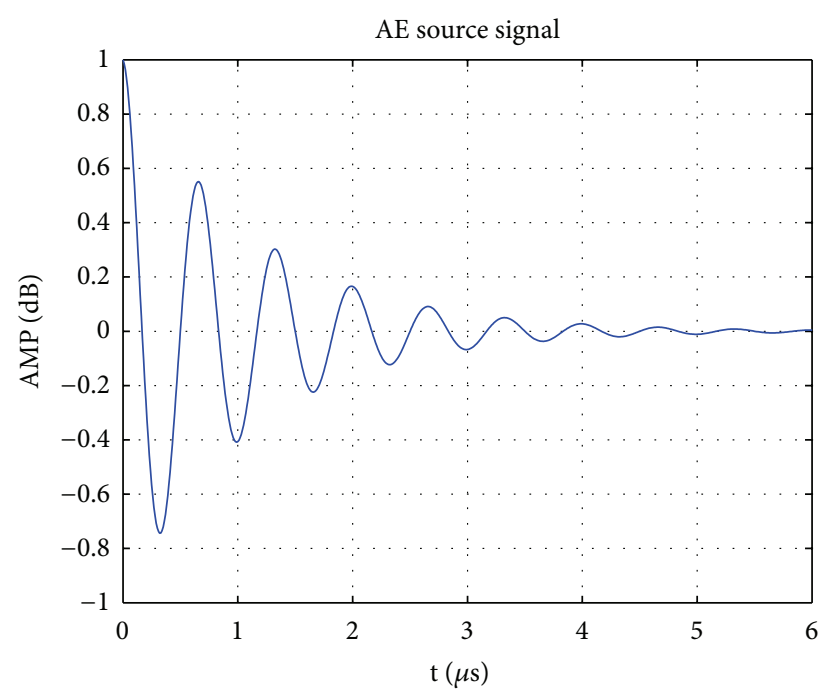

(a) AE source signal

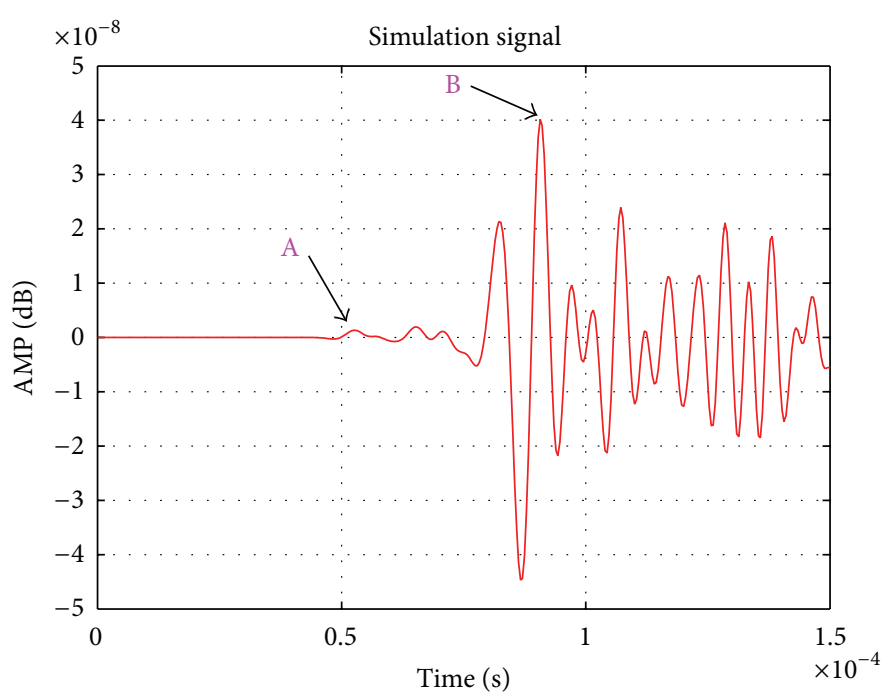

(b) Simulation signals (FE)

Figure 5: AE source and FE simulation signals.

$k$ at the corresponding sensor. $T_{k}^{0}$ is the time of measured occurrence of the event that originates the ray $k$.

The solution of (1) can be obtained iteratively with a process known as algebraic reconstruction technique (ART) $[16,20]$. The basic five steps of the ART algorithm are described as follows.

Step 1. An initial guess is defined for all $s_{i j}$, usually starting with a homogeneous case that is the same constant speed for all tomographic cells.

Step 2. The event location is calculated based on the values assigned for propagation speed of the signals.

Step 3. The arrival times of the signal at each sensor are calculated as

$$
t_{k}^{A}=t_{k}^{0}+\sum w_{i j}^{k} \cdot s_{i j}
$$

where $t_{k}^{A}$ is the time of theoretical arrival of the signal from ray $k$ at the corresponding sensor. $t_{k}^{0}$ is the time of theoretical occurrence of the event that originates the ray $k$.

Step 4. A correction is calculated for the $s_{i j}$ as

$$
\Delta s_{i j}=\frac{T_{k}^{A}-t_{k}^{A}}{N_{k}}
$$

where $N_{k}$ is the number of cells crossed by the $k$ th ray and $w_{i j}^{k}$ are approximated by zeros or ones.

Step 5. The tomographic cells crossed by the rays have its slowness updated by

$$
s_{i j}^{(g+1)}=s_{i j}^{(g)}+\lambda \cdot \Delta s_{i j}^{(g)},
$$

where $g$ is iterative number and $\lambda$ is a relaxation factor chosen between 0 and 2, which is used to assure the stability of the algorithm.

The process is repeated until convergence is obtained. Finally, a better estimate of the event locations and a mapping of the propagation speeds $c_{i j}$ of the signals inside the object are given as outputs.

\section{Numerical Simulation}

3.1. FE Model of Concrete Structure. In order to address the physical soundness of the AE tomography method, the ordinary concrete is chosen as the main material of the sample in the experiment and numerical simulation process, and its main components contain sand, cement, coarse aggregates and pores, water, and so on, which are a typical heterogeneous media. In addition, to satisfy the requirement of investigated object, a small concrete plate with $400 * 400$ $* 100 \mathrm{~mm}^{3}$ is built.

As this specimen is relatively small, some simplification and reasonable assumptions are made in the numerical simulation process; for example, concrete specimen is homogeneous, isotropic, and incompressible [21, 22]. Thus, main parameters of the concrete structure model are obtained as shown in Table 1.

The model of concrete structure is established using the finite element (FE) commercial package ABAQUS/Explicit, as shown in Figure 2.

3.2. Verification of FE Model. In order to verify the validity of the FE model, wave velocity measurement experiment is carried out by pencil lead break (PLB) in the simulation model of concrete structure (see Figure 3(a)). Blue dot near s1 is AE source. After AE is excited, the transit time of acoustic signal arrival is recorded by sensors ( 1 and s2), respectively; 


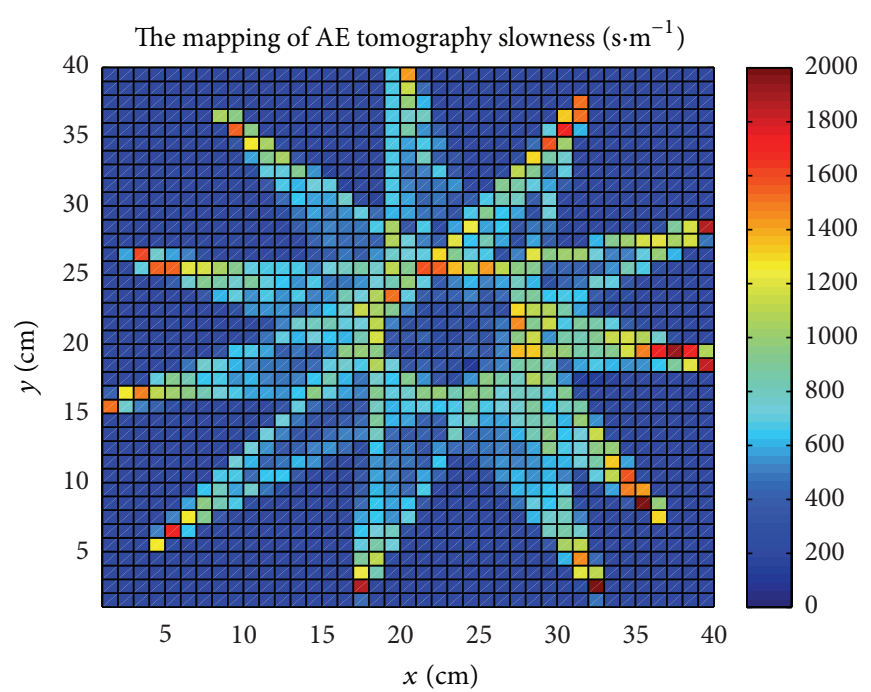

(a) $309 \mathrm{AE}$ events

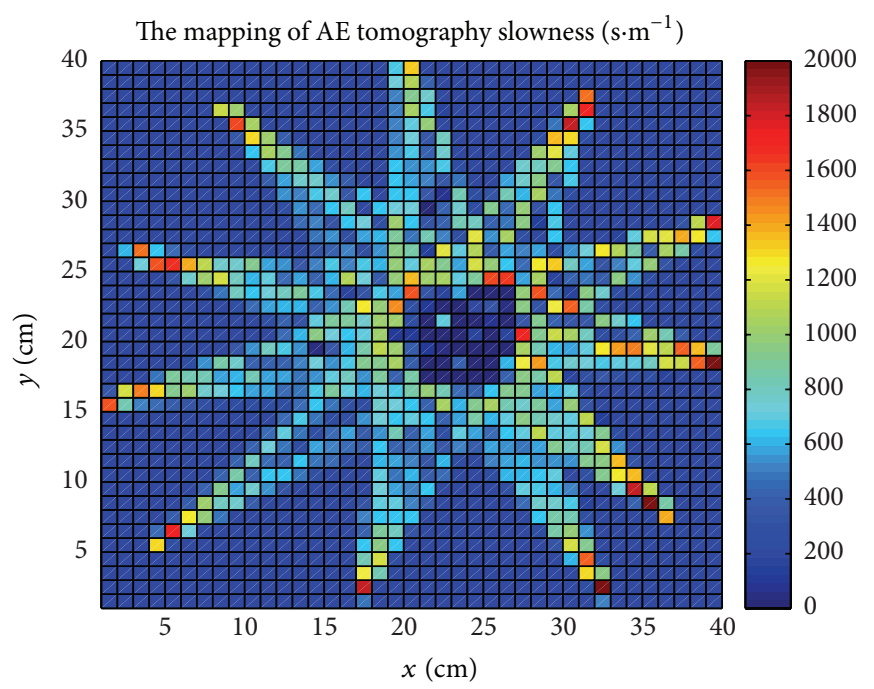

(c) $509 \mathrm{AE}$ events

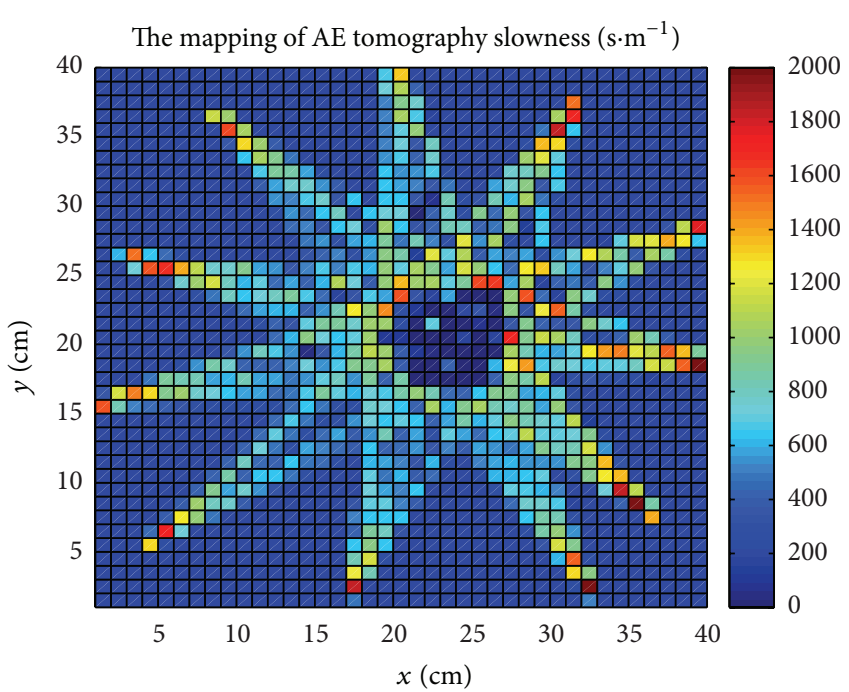

(b) $375 \mathrm{AE}$ events

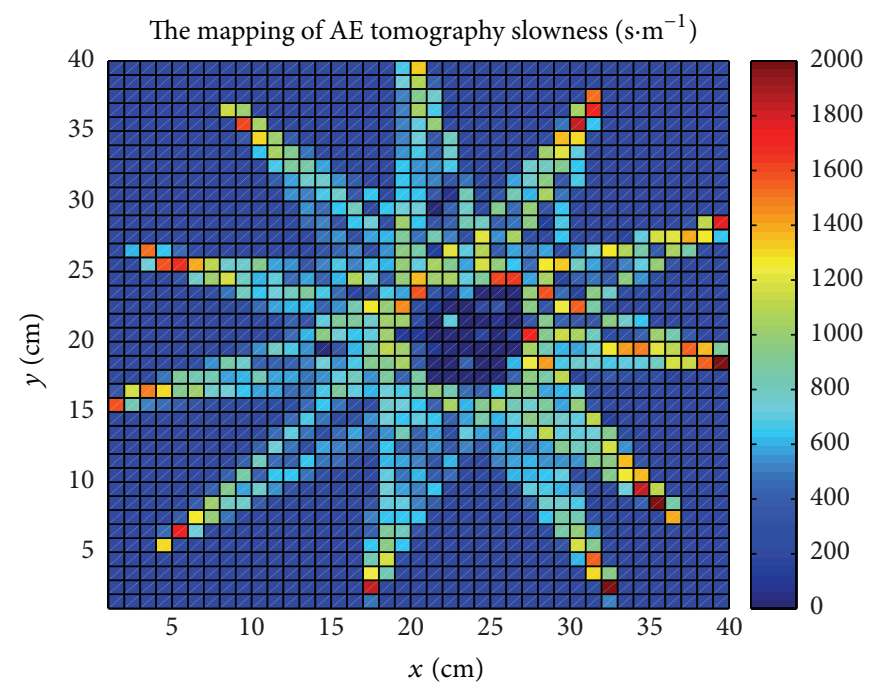

(d) $535 \mathrm{AE}$ events

FIGURE 6: AE tomography (simulation results).

TABLE 1: Main parameters of the concrete model.

\begin{tabular}{lc}
\hline Material parameter & Value \\
\hline Young's modulus E/Gp & 21.1 \\
Poisson ratio $\sigma$ & 0.167 \\
Density $\rho / \mathrm{kg} \cdot \mathrm{m}^{-3}$ & 2.050 \\
Yield stress $\varepsilon / \mathrm{Mpa}$ & 25.00 \\
Compression wave $\mathrm{m} / \mathrm{s}$ & 3950 \\
Shear wave $\mathrm{m} / \mathrm{s}$ & 2250 \\
\hline
\end{tabular}

the time difference of arrival at two sensors based on the peek at the points of B1 and B2 is calculated (see Figure 3(b)). And then, the wave propagation speed in the model is obtained according to linear location principle. This result is close to the actual measured velocity $(v=3250 \mathrm{~m} / \mathrm{s})$ in the in situ concrete experiment (see Figure 7(a): real concrete specimen). So the simplified FE model is effective and is suitable for real concrete structure simulation.

In addition, ABAQUS offers the energy conversation principle, and it is a criterion to judge whether the simulation process is reliable. It can be known by ABAQUS Analysis User's Manual [23] that the EF model is reliable if the kinetic energy of the deformable material to its internal energy is not less than $10 \%$ during mostly the simulation time. And the artificial strain energy to internal energy is not greater than $5 \%$. Finally the variations of energies are obtained in the simulation, and the results are in agreement with the energy criterion, as shown in Figure 4. So it can be concluded that the simplified FE model is reliable.

3.3. FE Results and Data Analysis. For each excited AE source event, time-domain waveform of AE source signal is shown in Figure 5(a). Point A is the occurrence time of signal arrival 


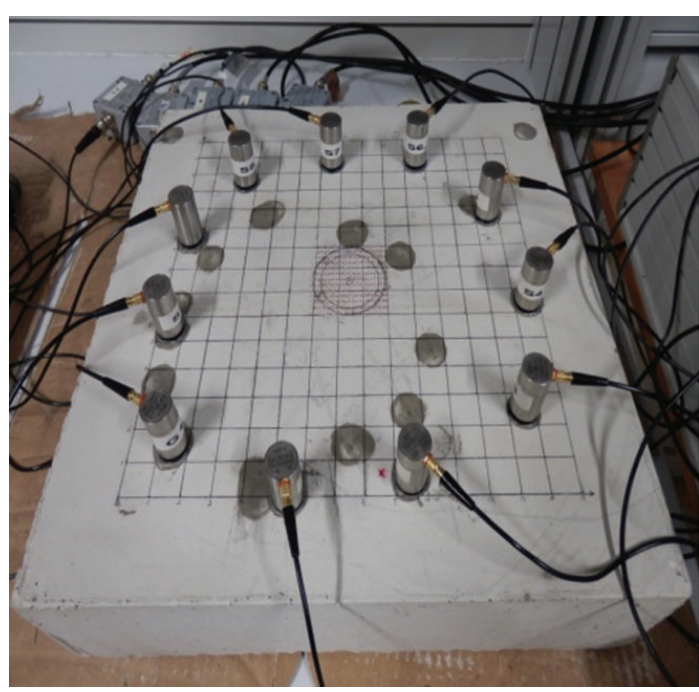

(a) Concrete sample with sensors on it

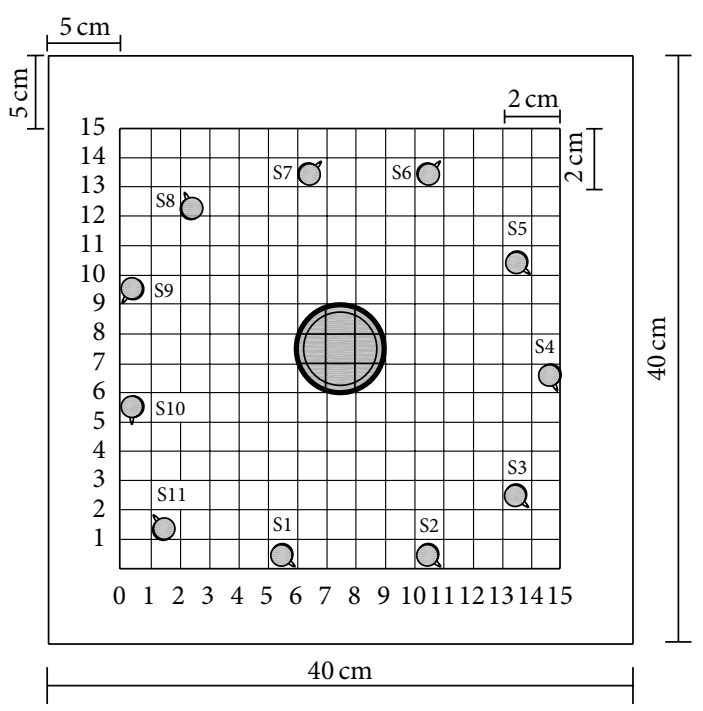

(b) Sensors layout

FIGURE 7: Experimental system of AE tomography.

and point $B$ is the peek time in the simulated time-domain waveform (see Figure 5(b)).

The simulation process was repeated for the complete data set, a total of more than five hundred AE events were excited randomly along the circumference of the damaged circle inside the FE model. Afterwards, the peak-arrival time of the time-domain signals received at each sensor was determined by using manual picking waveform ( $\mathrm{P}$ wave) data at the point B. Arrival-time difference series computed were served as input for the AE tomography algorithm; the simulation results of different $\mathrm{AE}$ events in the concrete structure were obtained. A mapping of the AE tomography (see Figure 6) was reconstructed, which included 309AE events, $375 \mathrm{AE}$ events, $509 \mathrm{AE}$ events, and $535 \mathrm{AE}$ events, respectively.

As shown Figure 6, it can be seen that a damaged circle location in the FE model of concrete structure is located and visualized by the $\mathrm{AE}$ tomography algorithm. As the number of $\mathrm{AE}$ events is increasing, each new $\mathrm{AE}$ event can lead to a better approximation in spatial velocity field. Wave speed changes in the defective region become more obvious than the other area in the model. Figures 6(a), 6(b), 6(c), and 6(d) display the results from the different $\mathrm{AE}$ events in the mapping of the AE tomography constructed and these results show a remarkable improvement in the $\mathrm{AE}$ tomographic image quality., More than three hundred of $\mathrm{AE}$ events, especially, such as $375 \mathrm{AE}$ events, are computed, the damaged circle position becomes pretty clear, and local damaged area slowness value arrives at the maximum in the tomographic image (see Figure 6(b)). A further increase of the number of $\mathrm{AE}$ events intends to improve the quality of the images automatically, but the results are not prominent (see Figure 6(c)). When the $\mathrm{AE}$ events continue to increase to about 535 $\mathrm{AE}$ events, the images remain unclear without significantly modifying its qualities (see Figure 6(d)). This result shows that the ray coverage of the tomography cells reaches a certain level, and a saturation behavior has occurred.

\section{Experiment}

4.1. AE Experiment. To confirm and calibrate the above numerical experiment, AE experiment under a planar location test setup was performed on concrete plate of $400 \times$ $400 \mathrm{~mm}$ with $100 \mathrm{~mm}$ of the thickness and a diameter $60 \mathrm{~mm}$ circle in the centre of specimen by using Hsu-Nielsen ( $\mathrm{H}$ $\mathrm{N}$ ) artificial sources. As the specimen was a relatively small concrete plate, and the density of $\mathrm{AE}$ sensors used was relatively high, some factors such as wave attenuation can be ignored. Eleven low-frequency sensors resonant at 25$80 \mathrm{kHz}$ (VS-30) were coupled directly to the sample using an acoustic couplant layer of silicone grease (see Figure 7(b)). Sensors sensitivity and calibration were evaluated by using the classical PLB (pencil lead break) technique. Sixteen channels Vallen AMSY-5 system equipment (Vallen, Europe $\mathrm{AE}$ team) was used as signal acquisition system in order to collect $\mathrm{AE}$ waveforms and data. Acquisition parameters configuration was shown in Table 2.

After configuration, the sample area was divided into a matrix with $n \times m=40 \times 40$ tomography cells, $2 \times 2 \mathrm{~cm}$ each as shown in Figure 7. Five of $\mathrm{H}-\mathrm{N}$ sources were conducted on each cell node around each sensor. Response of all sensors to the $\mathrm{H}-\mathrm{N}$ source was above $98 \mathrm{~dB}$ amplitude. It demonstrates that all sensors were correctly mounted and coupled. After this mandatory calibration testing, an $\mathrm{AE}$ source location test using $\mathrm{H}-\mathrm{N}$ artificial sources was implemented on the sample, and the time of arrival of each $\mathrm{AE}$ event to each sensor and the arrival sensors sequence orders were recorded with the equipment and software. Time of arrival was considered to be the classical first threshold crossing (FTC). The same as 


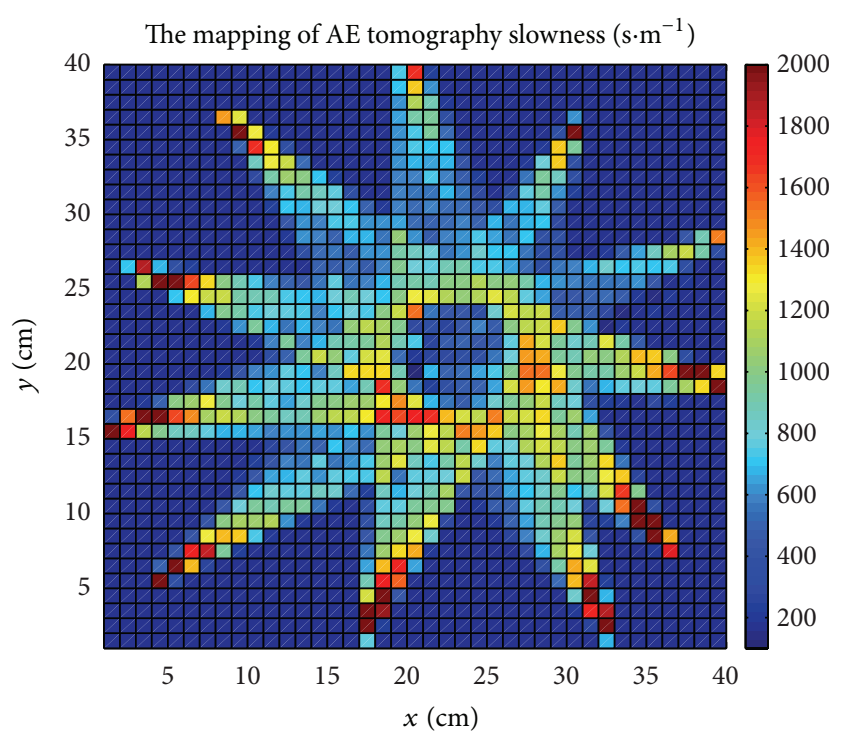

(a) $309 \mathrm{AE}$ events

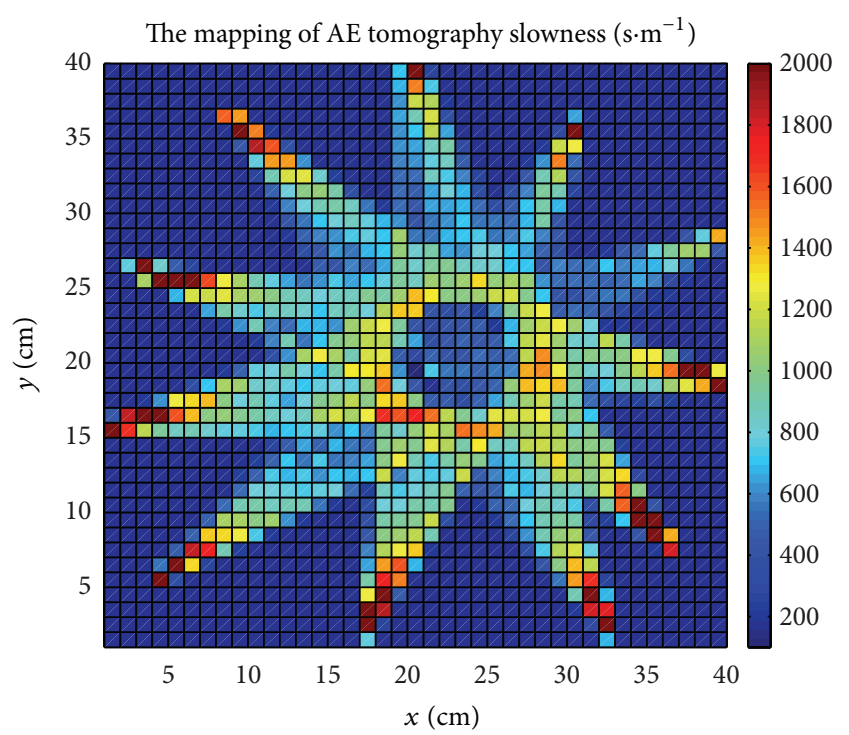

(c) $509 \mathrm{AE}$ events

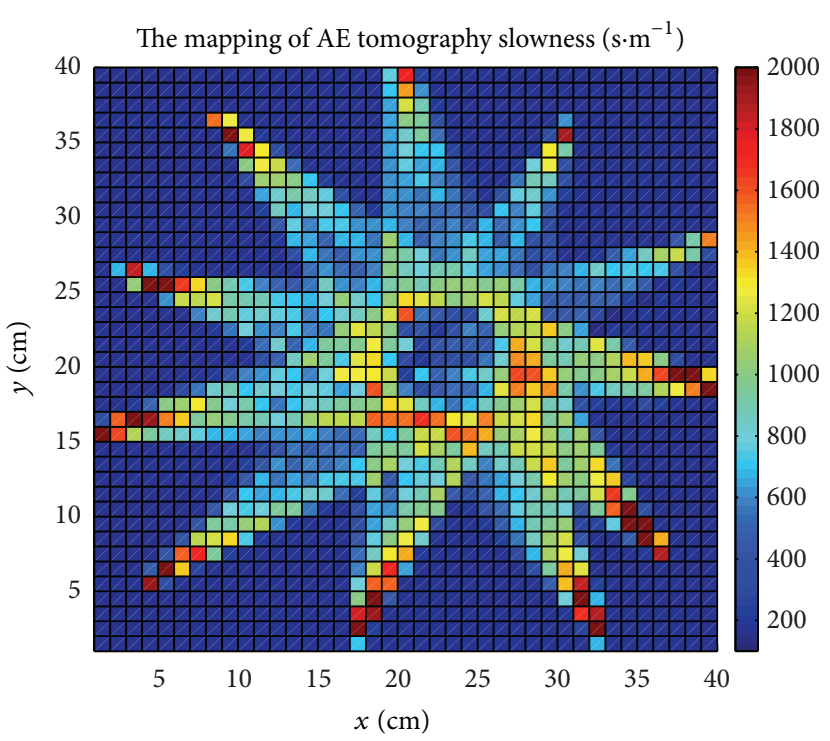

(b) $375 \mathrm{AE}$ events

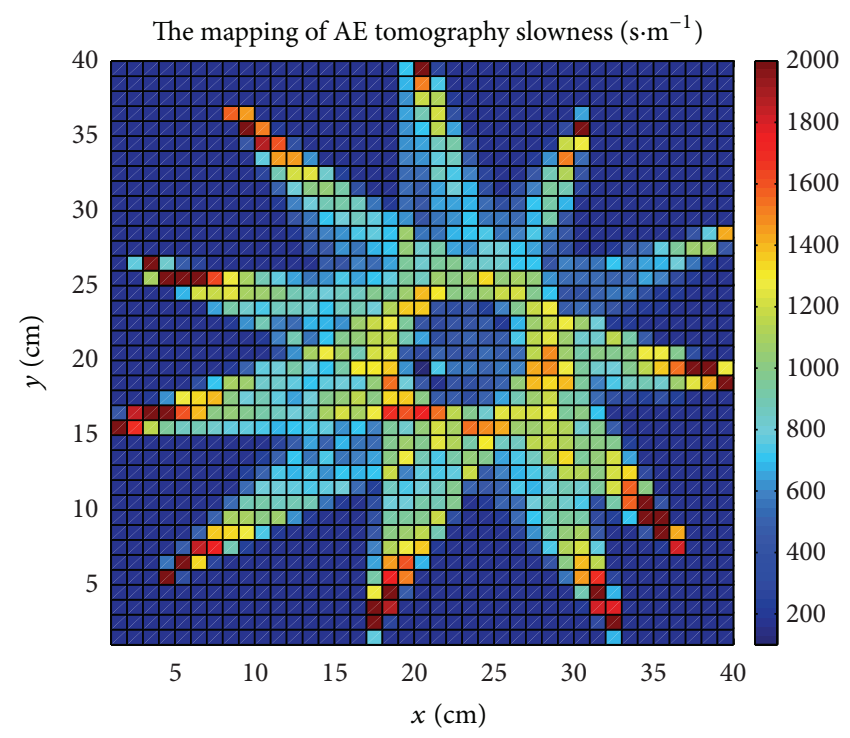

(d) $535 \mathrm{AE}$ events

Figure 8: AE tomography (experimental results).

TABLE 2: Acquisition parameters configuration.

\begin{tabular}{|c|c|c|c|c|c|}
\hline Threshold level & Preamplifier & Retrigger rate & Wave length & Digital filiter2 & Sample \\
\hline $30.6 \mathrm{~dB}$ ( $\mathrm{P}$ wave $)$ & $34 \mathrm{~dB}$ & 600 & 4096 & $25 \mathrm{kHz}-180 \mathrm{kHz}$ & $5 \mathrm{MHz}$ \\
\hline
\end{tabular}

simulation test, more than three hundred $\mathrm{AE}$ events were typically chosen for the AE tomography.

4.2. Experimental Results and Data Analysis. The initial measurement of propagation speed of the concrete plate was $3250 \mathrm{~m} / \mathrm{s}$. $\lambda$ was 0.05 . Arrival time differences at each sensor obtained in the experiment were input to a routine that performs the AE tomography algorithm on Matlab7.8 platform. A mapping of AE tomography was constructed for different $\mathrm{AE}$ event, respectively.
Figure 8 shows the influence of the number of AE events on the $\mathrm{AE}$ tomography during the experimental process. The corresponding images represent the wave speed model using $349 \mathrm{AE}$ events, $375 \mathrm{AE}$ events, $509 \mathrm{AE}$ events, and $535 \mathrm{AE}$ events. From Figure 8 a damaged circle in different images is clearly visible, which corresponds to the damaged circle location of the specimen. Compared with Figure 6, the similar conclusions can be drawn. As the number of AE events grows increasingly, the wave speed model becomes better and better and the image quality of $\mathrm{AE}$ tomography has a significant 


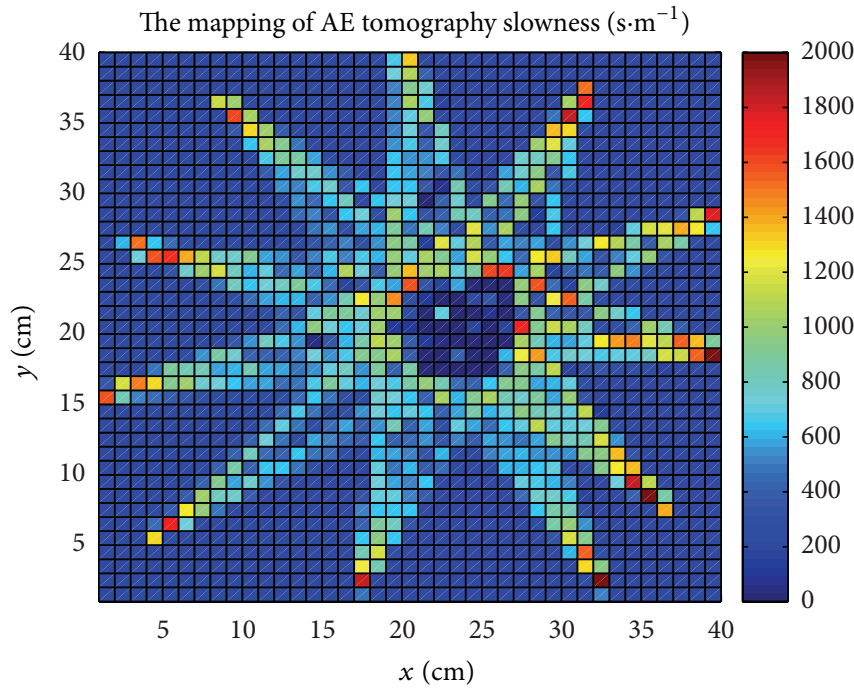

(a) FE simulation AE tomography location

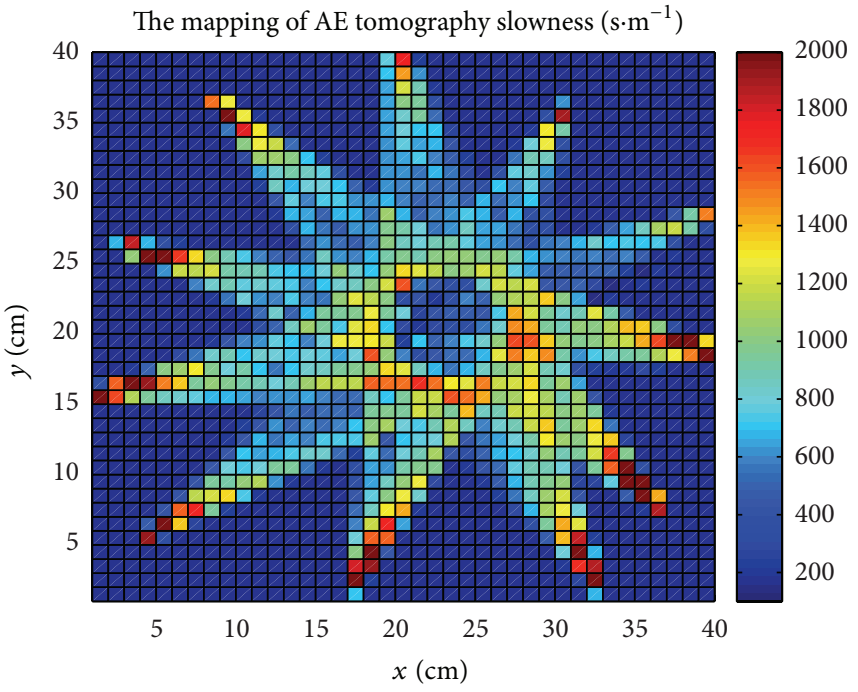

(b) Experiment $\mathrm{AE}$ tomography location

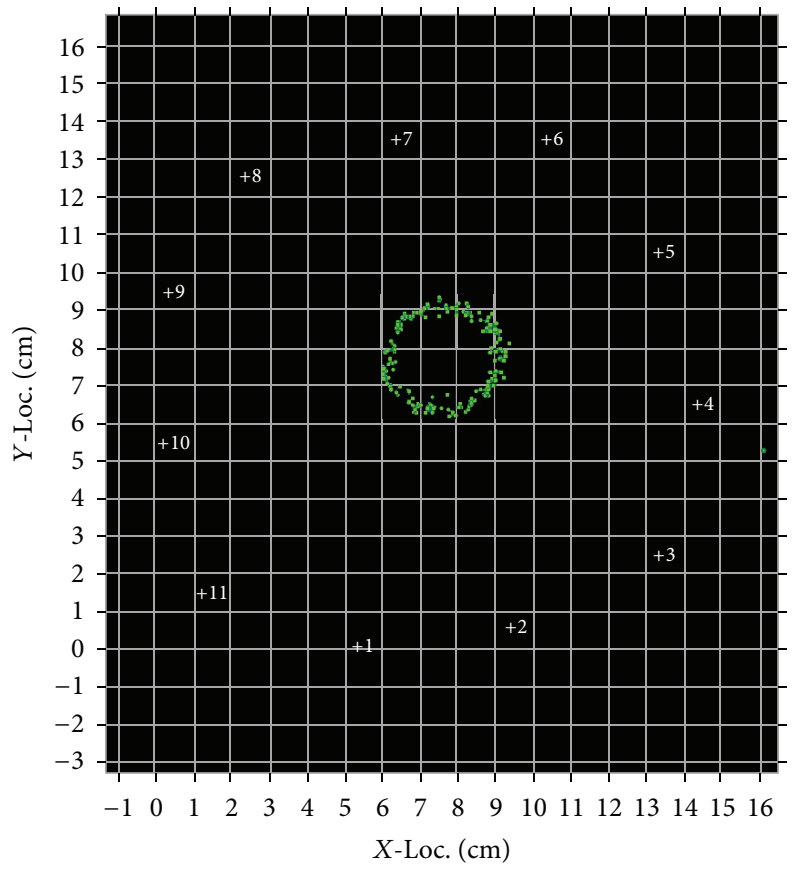

$\mathrm{Fl} 1 \backslash \mathrm{Fl} 3 \backslash \mathrm{Fl} 2 \backslash \mathrm{Fl} 4 \backslash \mathrm{Lc} 1 \backslash 2 \mathrm{D} 1$

- No filter

(c) Traditional TOA source location

Figure 9: TOA and AE tomography source location (375 AE events).

change at the beginning. After about three hundred AE events are dealt with, the overall trend of the model reaches the best, and a damaged circle location inside concrete sample becomes quite clear. Similar to the simulated test, a saturation behavior is observed after about five hundred AE events are obtained, which shows that the ray coverage of the tomography cells reaches a certain level. If the number of tomography cells is kept a constant, a further increase of the number of AE events would not automatically improve the quality of the image.

\section{Results and Discussion}

It can be seen from Figures 6 and 8 that the changing trend of each AE event is roughly the same, some artifacts in the tomographic images are observed, and it is most likely caused by the simple straight line approximation of the AE tomography model. The nonuniform ray converges of the model leading to large differences in the number of rays passing through the equally sized tomography cells may be another reason. However, when a saturation behavior of the tomography 
TABLE 3: Three hundred and seventy-five AE events source location errors (375AE).

\begin{tabular}{lccc}
\hline Algorithms & Vallen $(\mathrm{mm})$ & Simulation $(\mathrm{mm})$ & Experiment $(\mathrm{mm})$ \\
\hline ME & 7.599 & 7.330 & 7.3500 \\
MR & 42.110 & 39.000 & 39.300 \\
WAE & 7.641 & 7.695 & 7.7623 \\
SD & 1.124 & 1.0523 & 1.0596 \\
WASD & 0.1657 & 0.1501 & 0.1539 \\
\hline
\end{tabular}

images is obtained, image quality changes have a little effect on the precision of $\mathrm{AE}$ source location to some extent.

Since the locations of all $\mathrm{AE}$ events in the simulation and the experiment are prior knowledge, the accuracy of $\mathrm{AE}$ source location is further studied. Three hundred and seventy-five $\mathrm{AE}$ ( $375 \mathrm{AE}$ ) events are chosen to evaluate source location accuracy in traditional TOA location algorithm and AE tomography location algorithm (FE simulation and experiment), respectively. Source location results of three different methods are shown in Figures 9(a), 9(b), and 9(c). Meanwhile, mean error (ME), mean residual (MR), weight average error (WAE), standard deviation (SD), and weight average standard deviation (WASD) are considered to be the indexes to evaluate source location error. The error results are shown in Table 3.

As shown by Table 3 , simulation results are basically consistent in experiment results by using different methods. Traditional TOA (Vallen) error is bigger than AE tomography source location (simulation and experiment).

Figure 10 displays the similar results with Table 3 according to the different $\mathrm{AE}$ source location algorithms. The traditional TOA location error (Vallen) is the maximum. The simulation and the experiment results (AE tomography) have the similar trend. Figures 11 and 12 are partially enlarged AE source location results in the $X$-axis direction and $Y$-axis direction of Figure 10, respectively. From Figures 11 and 12, the same results with Figure 10 can be observed obviously due to partial enlarged AE source location; that is, TOA algorithm source locations (marked in red, Vallen) are obvious deviation from sample locations (marked in blue with dot). The simulation source locations (marked in blue with star) are overlapped in part with experiment source locations (marked in pink) in the specimen by using AE tomography method.

\section{Conclusions}

Using numerical simulation and experimental methods, the investigations on the $\mathrm{AE}$ tomography algorithm to improve $\mathrm{AE}$ event location in concrete structure are carried out, and the following conclusions have been reached.

(i) The finite element simulation (ABAQUS/Explicit) model of concrete structure is built. Simulated AE source is excited to produce AE signal and numerical data set is obtained to serve as input of AE tomography algorithm. Good simulation results are obtained.

(ii) Based on $\mathrm{AE}$ tomography principle, the $\mathrm{AE}$ tomography algorithm is successfully applied to concrete

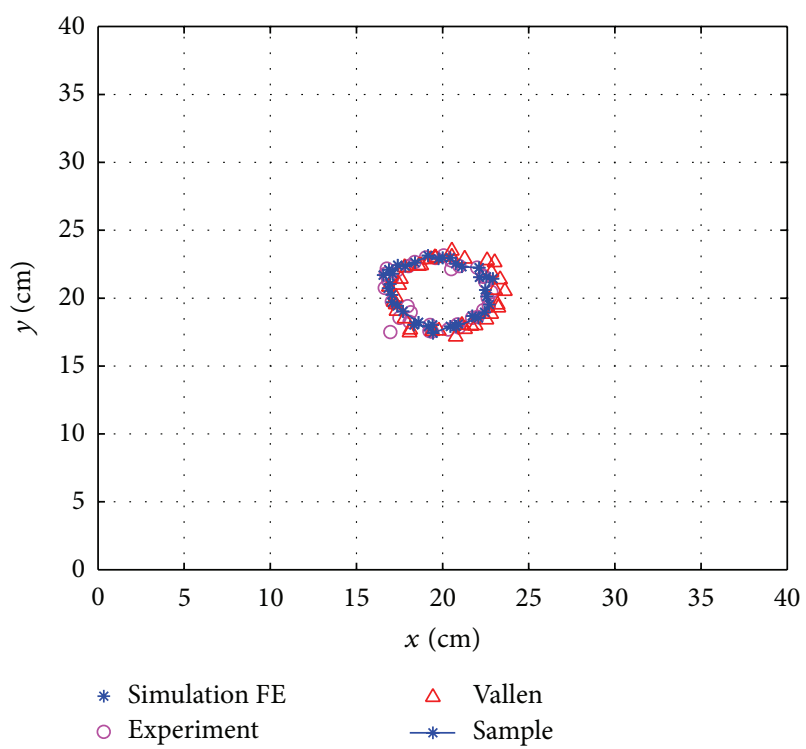

FIgURE 10: AE source location (Vallen, FE, experiment).

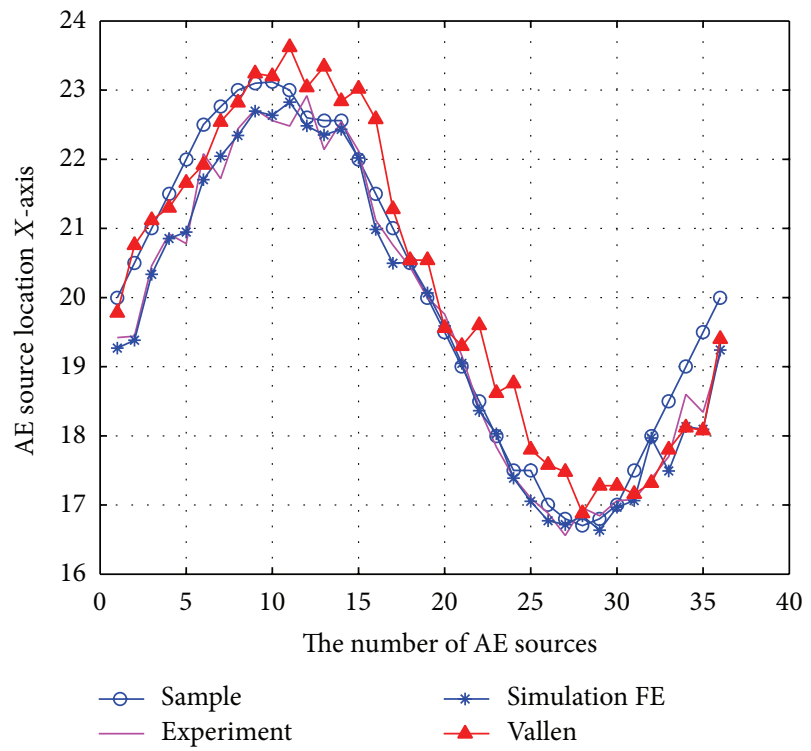

Figure 11: Partial enlarged source location ( $X$-axis).

structure for $\mathrm{AE}$ source location. It indicates that the $\mathrm{AE}$ tomography is an alternative source location method for AE technique applied analysis.

(iii) The located result of experiment has the similarities to the simulation result, which verifies the feasibility and reliability of the finite element model for $\mathrm{AE}$ tomography.

(iv) Compared with the results between AE tomography location (FE simulation and experimental) and traditional TOA location, the experimental results have good consistency with the FE simulation results from the point of source location error such as mean error and mean residual. A considerable improvement over 


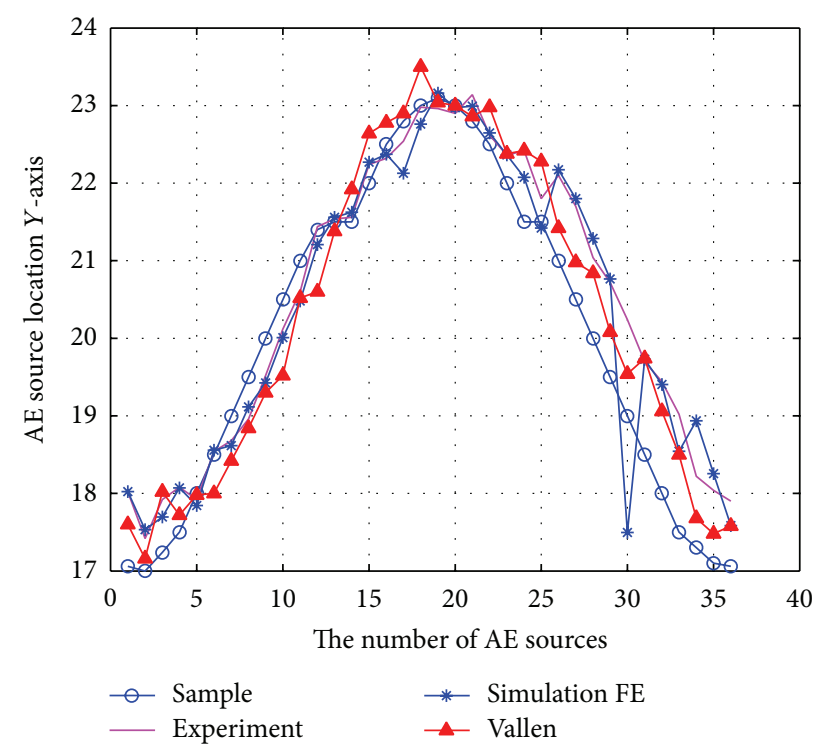

FIGURE 12: Partial enlarged source location ( $Y$-axis).

conventional TOA location algorithm is obtained by using the AE tomography location algorithm.

\section{Conflict of Interests}

The authors declare that there is no conflict of interests regarding the publication of this paper.

\section{Acknowledgments}

This work is supported by the National Natural Science Foundation of China (no. 51175079, no. 51305176) as well as the Fundamental Research Funds for the Central Universities (CXLX12_0079). The authors thank Mr. Oswaldo G dos Santos Filho, Brazil, for his long-term support and encouragement. Finally, the authors are grateful to the anonymous reviewers for their future reviewed work.

\section{References}

[1] T. Shiotani, S. Momoki, H. Chai, and D. G. Aggelis, "Elastic wave validation of large concrete structures repaired by means of cement grouting," Construction and Building Materials, vol. 23, no. 7, pp. 2647-2652, 2009.

[2] D. G. Aggelis and T. Shiotani, "Repair evaluation of concrete cracks using surface and through-transmission wave measurements," Cement and Concrete Composites, vol. 29, no. 9, pp. 700711, 2007.

[3] T. Shiotani, D. G. Aggelis, and O. Makishima, "Global monitoring of large concrete structures using acoustic emission and ultrasonic techniques: case study," Journal of Bridge Engineering, vol. 14, no. 3, pp. 188-192, 2009.

[4] T. Shiotani, D. G. Aggelis, and O. Makishima, "Global monitoring of concrete bridge using acoustic emission," Journal of Acoustic Emission, vol. 25, pp. 308-315, 2007.

[5] F. Ito, F. Nakahara, R. Kawano, S. S. Kang, and Y. Obara, "Visualization of failure in a pull-out test of cable bolts using
X-ray CT,' Construction and Building Materials, vol. 15, pp. 263270, 2001.

[6] E. Maire, V. Carmona, J. Courbon, and W. Ludwig, "Fast X-ray tomography and acoustic emission study of damage in metals during continuous tensile tests," Acta Materialia, vol. 55, no. 20, pp. 6806-6815, 2007.

[7] E. Kase and T. Ross, "Using seismic tomography and holography ground imaging to improve site investigation," in Proceedings of the No-Dig Conference, New Orleans, La, USA, 2004, paper no. C-4-02.

[8] L. Liu and T. Guo, "Seismic non-destructive testing on a reinforced concrete bridge column using tomographic imaging techniques," Journal of Geophysics and Engineering, vol. 2, no. 1, pp. 23-31, 2005.

[9] A. A. Shah and Y. Ribakov, "Effectiveness of nonlinear ultrasonic and acoustic emission evaluation of concrete with distributed damages," Materials and Design, vol. 31, no. 8, pp. 3777$3784,2010$.

[10] R. K. Miller and P. McIntire, "Acoustic emission testing," in NDT Handbook, vol. 5, American Society for Non-Destructive Testing, Columbus, Ohio, USA, 1987.

[11] H. J. Rindorf, "Acoustic emission source location in theory and in practice," Bruel and Kjaer Technical Review, vol. 2, pp. 3-44, 1981.

[12] R. Pullin, Structural integrity monitoring of steel bridges using acoustic emission techniques [Ph.D. thesis], Division of Mechanical Engineering and Energy Studies, 2001.

[13] Division of Mechanical Engineering and Energy Studies, University of Wales, Cardiff, UK, 2001.

[14] K. L. Rens, D. J. Transue, and M. P. Schuller, "Acoustic tomographic imaging of concrete infrastructure," Journal of Infrastructure Systems, vol. 6, no. 1, pp. 15-23, 2000.

[15] F. Schubert, "Tomography techniques for acoustic emission monitoring," in Proceedings of the 28th European Conference on NDT, Berlin, Germany, September 2006, ECNDT2006.

[16] J. A. Baron and S. P. Ying, "Acoustic emission source location," in Non-Destructive Testing Handbook, American Society for NonDestructive Testing, Columbus, Ohio, USA, 1987.

[17] A. C. Kak and M. Slaney, Principles of Computerized Tomographic Imaging, IEEE Press, New York, NY, USA, 1988.

[18] N. Diamanti, A. Giannopoulos, and M. C. Forde, "Numerical modelling and experimental verification of GPR to investigate ring separation in brick masonry arch bridges," NDT \& $E$ International, vol. 41, no. 5, pp. 354-363, 2008.

[19] K. M. Holford and D. C. Carter, "Acoustic emission source location," Key Engineering Materials, vol. 167, pp. 162-171, 1999.

[20] F. Schubert, "Basic principles of acoustic emission tomography," Journal of Acoustic Emission, vol. 22, pp. 147-158, 2004.

[21] D. G. Aggelis, "Damage characterisation of inhomogeneous materials: experiments and numerical simulations of wave propagation," Strain, vol. 47, no. 6, pp. 525-533, 2011.

[22] S. Q. Fan, S. D. Zhao, Q. Zhang, and Y. Y. Li, "Plastic mechanism of multi-pass double-roller clamping spinning for arc-shaped surface flange," Chinese Journal of Mechanical Engineering, vol. 26, no. 6, pp. 1127-1137, 2013.

[23] ABAQUS, Inc., ABAQUS Analysis User's Manual, Version 6.8, 2008. 


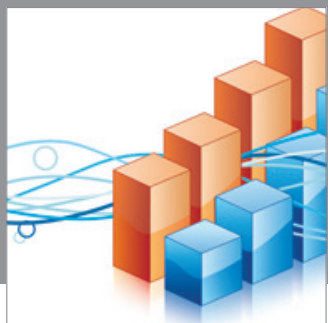

Advances in

Operations Research

mansans

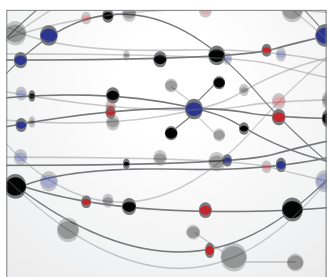

The Scientific World Journal
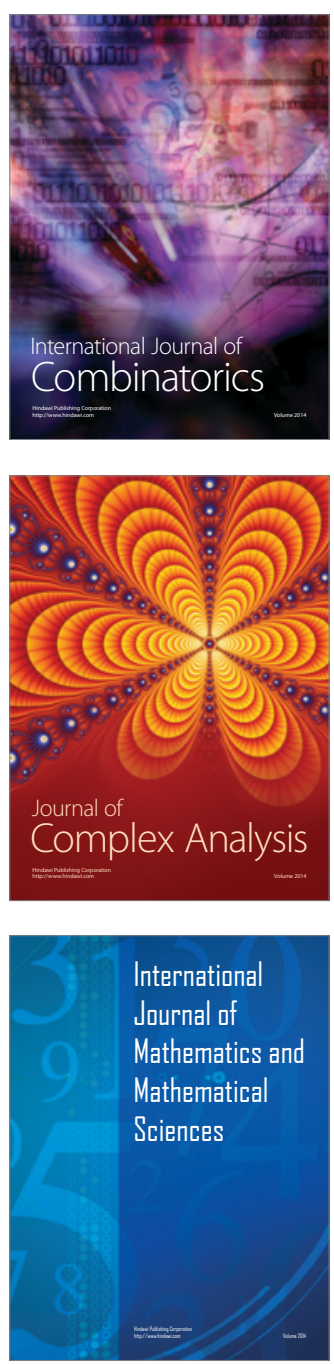
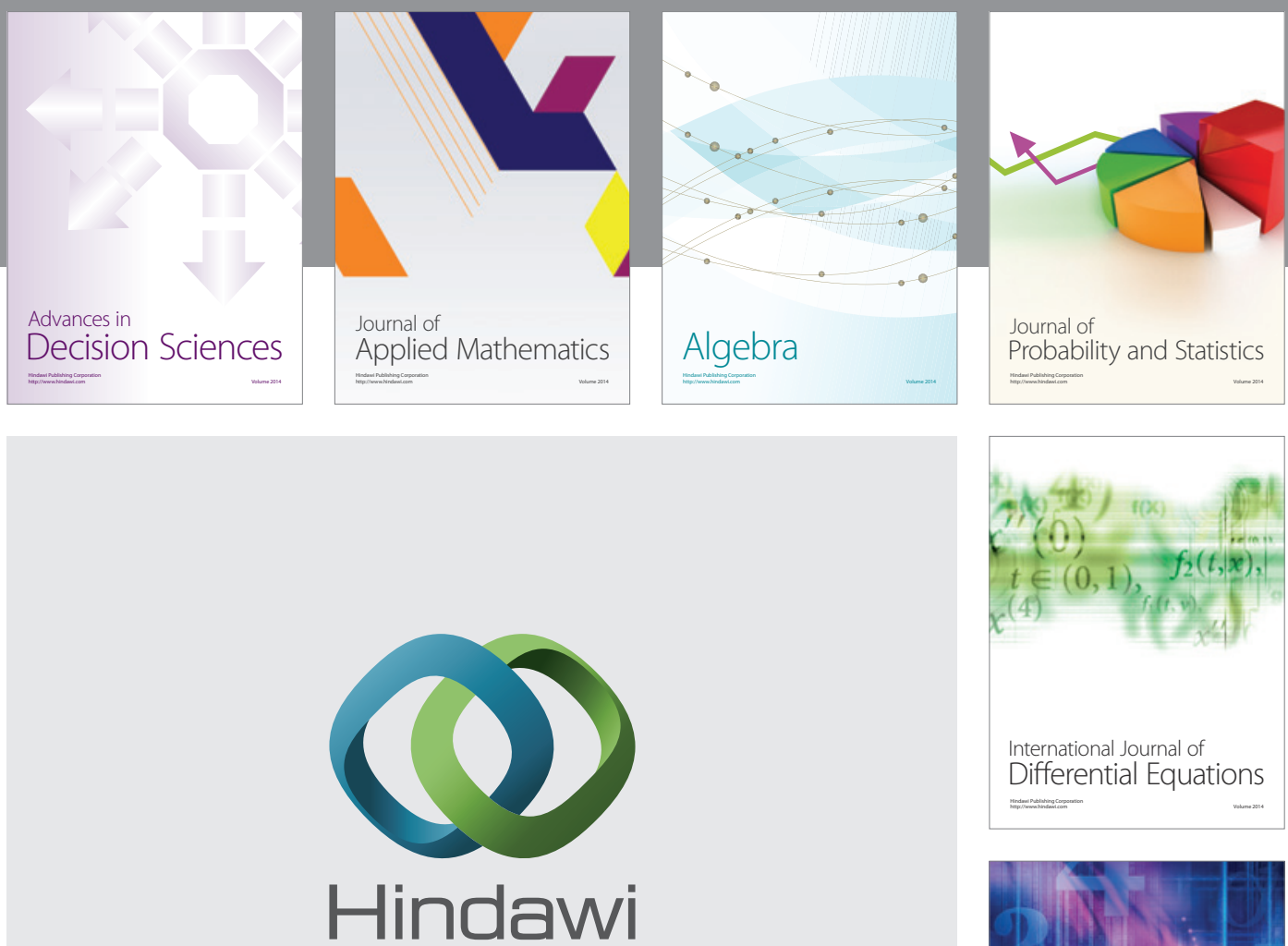

Submit your manuscripts at http://www.hindawi.com
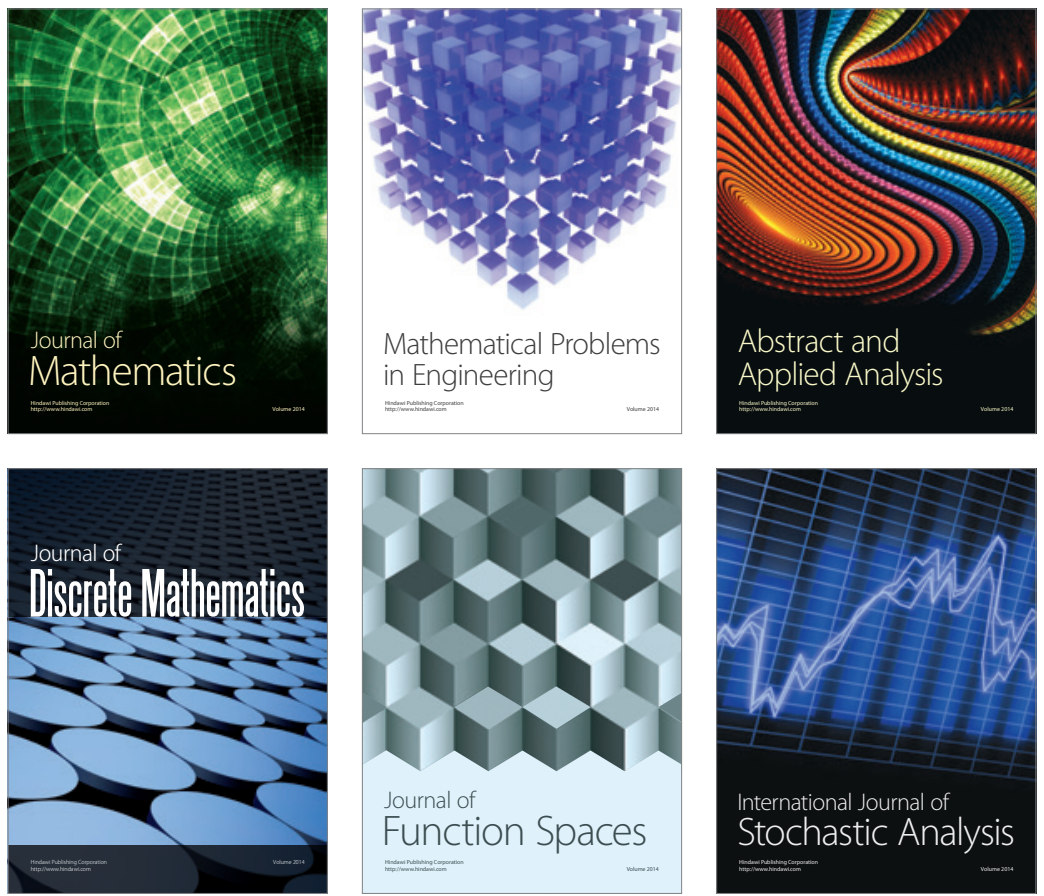

Journal of

Function Spaces

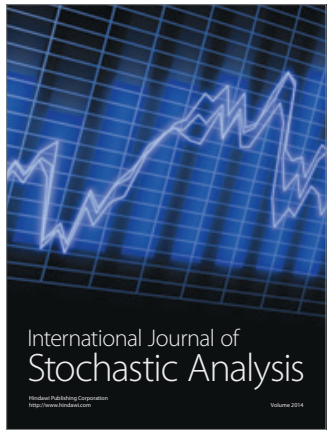

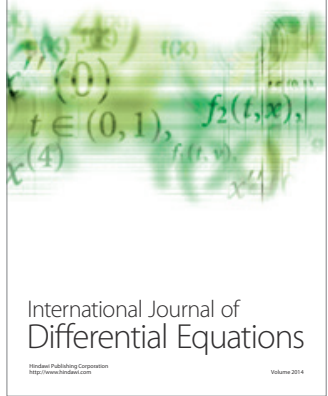
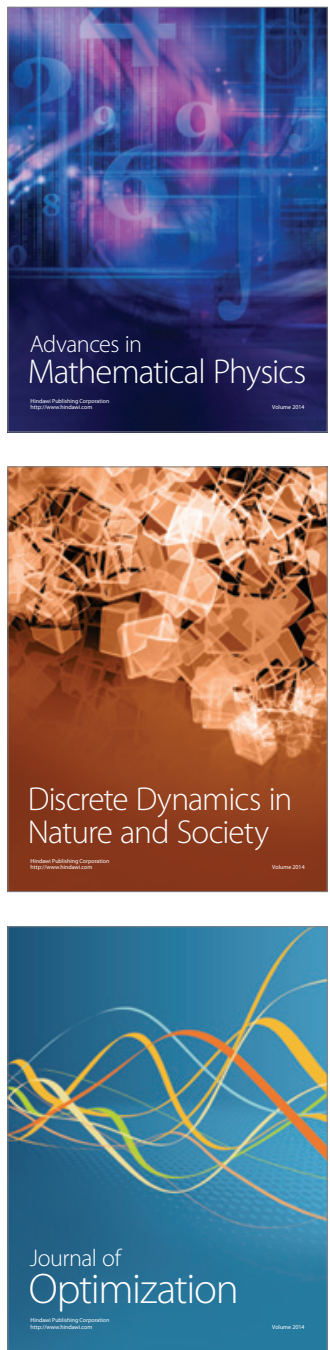